\title{
Estratégias de ensino da matemática utilizando Software Livre na escola pública
}

\author{
Karina Letícia Júlio Pinto ${ }^{1}$, Lívia Naiara Andrade ${ }^{2}$ \\ ${ }^{1}$ Instituto Federal do Rio Grande do Sul- IFRS- Porto Alegre- RS- Brasil \\ ${ }^{2}$ Universidade Federal de Lavras- UFLA- Lavras- MG- Brasil \\ karina.leticia21@hotmail.com, livia.naiara.andrade@gmail.com
}

\begin{abstract}
This article presents the application of shop math related to software Gcompris to elementary school students in an educational institution to the public. The discipline of mathematics is the weak point of many students, on the other hand new technologies are a strong point of this new generation. Thus, the software Gcompris can be an ally in the teachinglearning process of mathematical concepts. It has been found that the use of this educational program aligned to the curriculum content made the learning more attractive and meaningful. In addition to contributing to the training of the student, with the improvement of motor skills.

Resumo. Este artigo apresenta a aplicação da oficina de matemática referente ao software Gcompris aos alunos do ensino fundamental em uma instituição de ensino pública. A disciplina da matemática é o ponto fraco de muitos alunos, por outro lado as novas tecnologias são um ponto forte dessa nova geração. Assim, o software Gcompris pode ser um aliado no processo de ensino-aprendizagem de conceitos matemáticos. Verificou-se que o uso desse programa educativo alinhado aos conteúdos curriculares tornou o aprendizado mais atrativo e significativo. Além de contribuir na formação do aluno, com o aprimoramento das habilidades motoras.
\end{abstract}

\section{Introdução}

A matemática desempenha um papel importante na formação do indivíduo, porém o Relatório anual do Movimento Todos Pela Educação avaliou diretrizes e metas Escolares de 2011 e apontou que a disciplina da matemática é o ponto mais fraco de alunos concludentes do $3^{\circ}$ ano do Ensino médio, além de ser a que mais reprova na escola, é tarefa difícil encontrar alunos que gostem dessa disciplina. No ensino fundamental a situação não é diferente, segundo dados do Ministério da Educação (MEC), em 2003, 51,6\% dos alunos da $4^{\text {a }}$ série não tinham adquirido os conhecimentos matemáticos apropriados a essa faixa de escolarização e estavam em um estado "crítico" ou "muito crítico". Muitos alunos já chegam na escola com o discurso do senso comum: "matemática é para poucos" ou "matemática é muito difícil" e acabam criando barreiras para aprender a disciplina.

Não se sabe ao certo porque os alunos não gostam da disciplina da matemática, mas algumas pesquisas (GOMES, 2006; CORREA, MCLEAN, 1999; VASCONCELOS, 2000) tentam explicar esse desconforto e a melhor forma de ensinála. Para Gomes (2006), o desconforto provém dos conceitos que temos ao longo de nossa formação, que remete a memorizar o conteúdo para aprender matemática sem 
compreendê-la. Assim, Ambrosio (1989) destaca que "os alunos acham que a matemática é um corpo de conceitos verdadeiros e estático". Nessa perspectiva, ele já possui um padrão de resolução ensinado pelo professor, não permitindo ver novas possibilidades. Porém, quando não consegue chegar a solução, desistem de solucionar um problema matemático, afirmando não ter aprendido aquele tipo de questão.

Por outro lado, se a disciplina não está sendo ensinada de forma com que o aluno possa atrelar a teoria e a prática é preciso se apropriar das diferentes maneiras de ensinar ou através delas criar novas propostas para que o aluno tenha uma aprendizagem que faça sentido. Assim, uma das estratégias é usufruir das novas tecnologias alinhadas ao ensino. Os Parâmetros Curriculares Nacionais (1997) apontam os computadores como um recurso de didático com grande potencial para ser utilizado no processo de ensino-aprendizagem dos alunos, e indica que pelo seu caráter lógico-matemático pode ser um aliado ao processo de desenvolvimento cognitivo.

Portanto, esse relato de experiência retrata a utilização de um software livre (Gcompris) para ensinar conceitos básicos da matemática, com a turma do $2^{\circ}$ ano do ensino fundamental de uma escola pública. Diante do exposto, o problema que motiva a pesquisa leva ao seguinte questionamento: "Quais as implicações da utilização do software livre Gcompris, para o ensino de conceitos básicos da disciplina matemática, na formação do aluno?”.

\section{Metodologia}

Foi desenvolvida uma oficina com uma turma de 15 alunos do $2^{\circ}$ ano do Ensino Fundamental I no laboratório de informática de uma escola pública de Porto Alegre/RS. A oficina foi aplicada com auxílio da professora regente da turma e no horário normal da aula. O software utilizado na oficina é o Gcompris (Figura 1), ele é um aplicativo educacional de código aberto, criado pelo engenheiro de software francês Bruno Coudoin no ano 2000. Esse software compreende numerosas atividades para crianças de idade entre 2 e 10 anos. Atualmente o GCompris oferece mais de 100 atividades e está em constante evolução (Gcompris, 2016). As atividades são de caráter educacional e encontram-se divididas em uma lista de categorias.

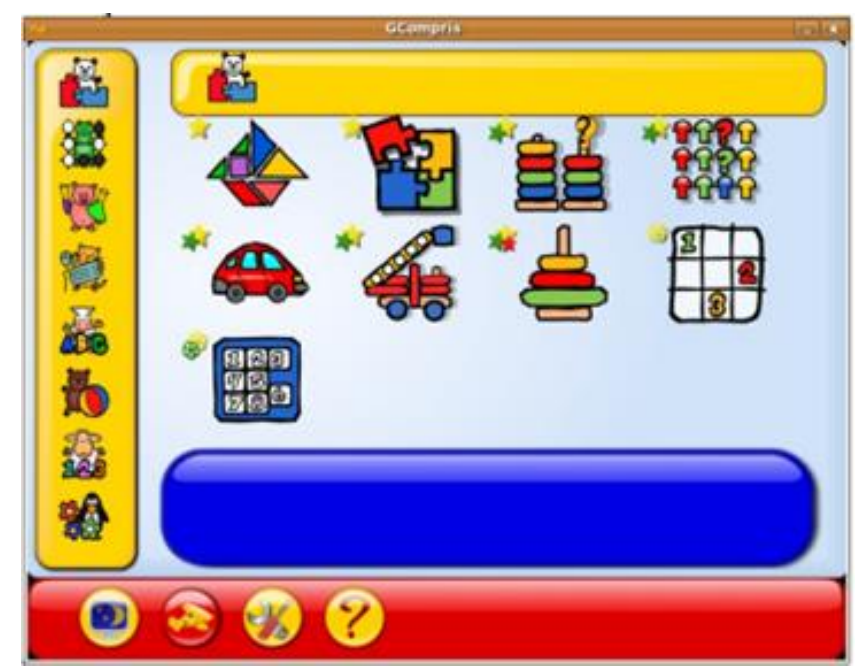

Figura 1. Página inicial do software Gcompris 
Para a oficina foram realizadas as atividades "ligue os pontos" e "contagem de itens" ambas atividades presentes na categoria matemática e subcategoria numeração do jogo. O objetivo pedagógico da proposta foi ensinar os conceitos básicos da matemática (sequência numérica, contagem, raciocínio e lógica-matemática) por meio de um software educacional. Segundo Piaget (1993), após os sete anos a criança atinge uma forma superior de equilíbrio de pensamento que gera a noção de operações que se aplica a realidades diversas. Assim, a ação de reunir (adição lógica) e as reuniões invertidas (subtração) são operações, porém é importante permitir que a criança construa o conceito que envolve a operação. Diferentemente da forma tradicional, os jogos digitais apresentam-se como uma ferramenta dinâmica e atrativa para os alunos. Porém, é interessante destacar que a aplicação dessas ferramentas na escola também exige uma reflexão constante do professor e suas práticas.

\section{Resultados e discussões}

Primeiramente, realizou-se uma fala inicial com os alunos em sala de aula, onde foi apresentada a proposta da atividade no laboratório de informática. O primeiro ponto positivo foi observado na conversa em sala, em que os alunos demonstraram muito interesse pela atividade e no momento da prática por meio dos computadores nenhuma criança deixou de realizar a atividade proposta.

Na primeira atividade intitulada "ligue os pontos" (Figura 2), o aluno seguiu a sequência numérica proposta clicando nos números ordenadamente.

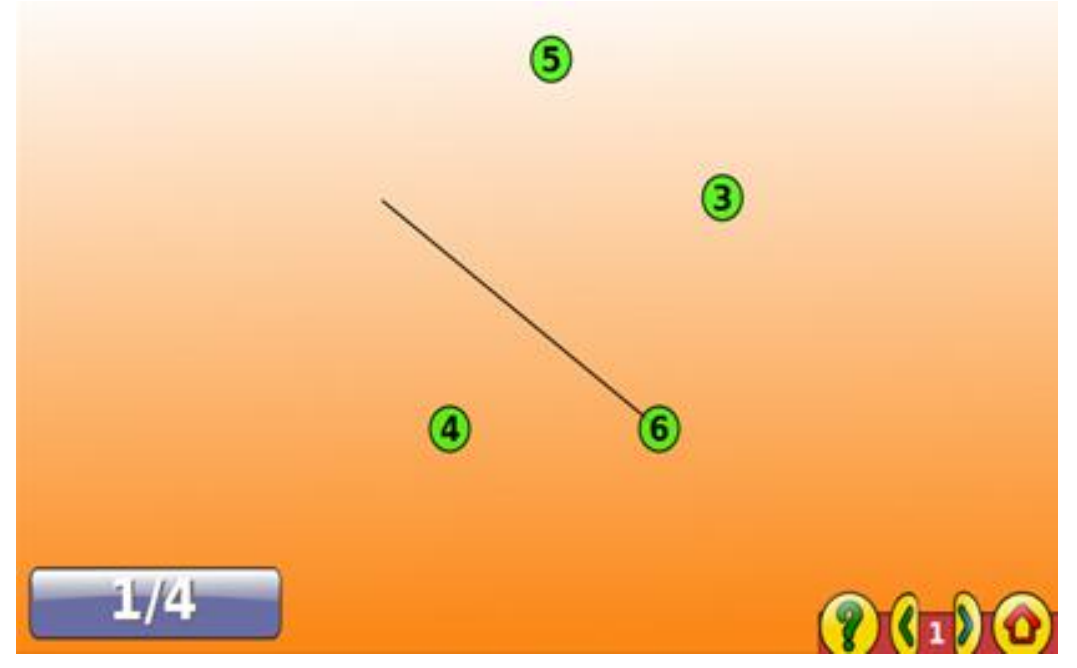

Figura 2. Atividade ligue os pontos

Quando completam a sequência, uma figura foi formada e em seguida foi proposto um novo nível com aumento da numeração. Haviam alunos que completavam a proposta apresentada com mais destreza, possibilitando a colaboração com colegas que possuíam dificuldades na execução. Percebeu-se que 9 alunos apresentaram dificuldades nas atividades de numeração, mas ao perceberem que concluindo a sequência era formado uma figura, ficaram motivados em realizar o exercício solicitando a ajuda da professora e dos colegas. Para Vygotsky (1998), quando uma criança não consegue resolver um problema por si mesma, ela pode ter sucesso com a colaboração de um adulto ou de um colega com o nível mais alto de competência, 
refere-se aos princípios da Zona de Desenvolvimento Proximal- ZDP. A ZDP é como uma ponte que liga o desenvolvimento real (o que o aluno já sabe) ao desenvolvimento potencial (o que o aluno poderá aprender).

Verificou-se ainda que através do jogo os alunos despertaram o interesse pelo conteúdo, visto que todos realizavam as atividades e criavam diversas estratégias para avançar nas etapas do jogo. Para Roland (2004) as crianças e os adolescentes gostam de jogar, pois é uma forma divertida de aprender, assim proporciona aos alunos motivação, além de hábitos de persistência em realizar tarefas e desafios. Para Rose (2012), as ações de clicar, arrastar/solta e movimentar o mouse para executar o jogo colaboram com as habilidades motoras vinculadas principalmente a escrita. Porém, ainda há muitos professores que consideram que as atividades com jogos são inúteis e sem finalidades educativas (Neto, 2013).

A proposta seguinte contemplava a atividade de contagem de itens (Figura 3). O plano de fundo dessa atividade é uma tartaruga, na tela aparece itens que o jogador deverá contar e registrar no retângulo da lateral direta da tela. Quando a resposta correta for digitada o jogador avança para o próximo nível.

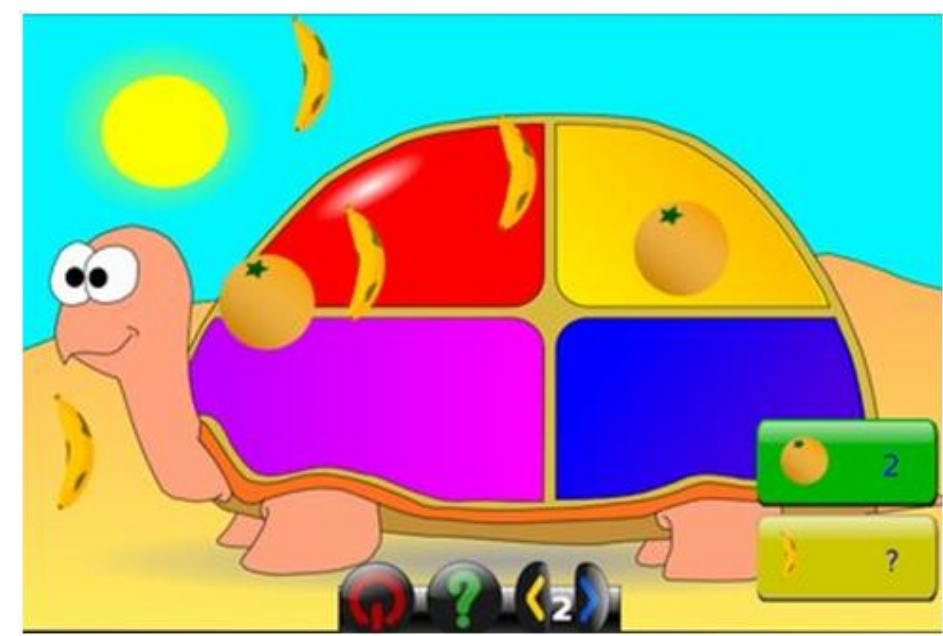

Figura 3. Atividade contagem de objetos

Quando os alunos iniciaram essa atividade a grande parte da turma considerou muito fácil a contagem dos objetos até o terceiro nível. Os elementos (banana, laranja, copo...) apareciam misturados e ao contar os alunos deveriam saber o total de cada um separadamente, assim foi possível observar que a primeira ação dos alunos foi a de separar os objetos em grupos na tela do jogo e terem a necessidade de colocar o dedo na tela do computador para ter certeza da contagem realizada. Dentre os alunos 5 solicitaram a ajuda da professora e/ou do colega que estava ao lado. Mesmo diante das dificuldades os alunos continuavam motivados na realização da atividade, e mesmo sendo o primeiro contato com o jogo demonstraram habilidades de exploração, percepção e concentração na realização da proposta. Houve momentos de conflito em que a aluna 1 não concordou com a contagem realizada pela aluna 2. De acordo com Kamii (1992) por meio do conflito é possível realizar negociações que permitem organizar colocando as coisas em relação e desenvolver a coerência e mobilidade do pensamento.

Ao final das atividades os alunos foram questionados oralmente sobre suas 
concepções referentes a oficina desenvolvida. Todos os alunos consideraram muito positiva a oficina e sugeriram a continuação da proposta nas aulas contemplando também outras disciplinas. A professora regente da turma relatou que não conhecia esse software e que pretende desenvolver projetos que o utilize de modo interdisciplinar. A diretora que também acompanhou a proposta da atividade, mediante ao sucesso da proposta, se comprometeu em divulgar na reunião pedagógica para outros professores da escola que também não conhecem o software.

\section{Considerações finais}

Esse artigo apresentou a aplicação de uma oficina com o software Gcompris para alunos do $2^{\circ}$ ano de uma escola pública, as atividades propostas contemplavam o conteúdo referente a disciplina matemática. Verificou-se que o uso dos recursos tecnológicos alinhados aos conteúdos curriculares tornou o aprendizado mais atrativo e significativo. Além de contribuir na formação do aluno, com o aprimoramento das habilidades motoras. Assim, O software Gcompris é um novo recurso para utilização desses alunos, visto que o relato da professora apontou a não utilização do software antes da aplicação dessa oficina.

Sendo assim, a utilização do software livre Gcompris no ensino dos alunos implicaram na motivação do aluno na realização das atividades, bem como no desenvolvimento sensorial, dentre eles identificação da coordenação motora, uma forma de aprimorar a escrita e a inclusão digital. Ainda foram observados aspectos como o reconhecimento de números e sequência matemática.

É importante ressaltar que o apoio da direção da escola e da professora da turma no desenvolvimento da oficina foi favorável, pois apontaram o projeto como propício ao desenvolvimento da turma e as propostas da escola. Destaca-se que diante dos resultados satisfatórios do projeto, a equipe diretiva da escola afirmou dar continuidade na utilização do software que antes era desconhecido pela equipe escolar, além de citar a possibilidade de criar projetos internos com o software para outras turmas da escola que não foram contempladas com esse. Pretende-se num futuro próximo aplicar esse projeto em outras escolas e incorporar uma formação do professor para ele possa conhecer o software e utilizá-lo atrelado a prática pedagógica.

\section{References}

Ambrosio, B. S. (1989) "Como ensinar matemática hoje”. Temas e debates, v. 2, n. 2, p. 15-19.

Cavalcanti, P. L.; Ferreira, J. C. (2011) "Análise descritiva do software educacional GCompris”. In: Anais do Simpósio Brasileiro de Informática na Educação.

Correa, Jane; MCLEAN, Morag. Era uma vez... um vilao chamado matemática: um estudo intercultural da dificuldade atribuída matemática. Universidade Federal do Rio Grande do Sul, 1999.

Gcompris (2016) Disponível em: < http://gcompris.net/index-pt_BR.html >. Acesso em: Jun. 2016.

Gomes, M. G. et al. (2006) “Obstáculos na aprendizagem matemática: identificação e busca de superação nos cursos de formação de professores das séries iniciais. 2006. 
V Congresso Brasileiro de Informática na Educação (CBIE 2016)

Anais dos Workshops do V Congresso Brasileiro de Informática na Educação (CBIE 2016)

Inep (2016) Disponível em: < http://www.inep.gov.br/> . Acesso em: Jun. 2016.

Kamii, C. A criança e o número: implicaçöes educacionais da teoria de Piaget para a atuação junto a escolares de 4 a 6 anos. Papirus Editora, 1992.

Piaget, J. Seis estudos de psicologia. trad. de M. A. M. D’Amorim, 1993.

Real, L. M. C.; Picetti, Jaqueline S. Aprendizagens por possibilidades de deslocamentos em um Laboratório de Informática: um estudo de caso no Ensino Fundamental. In: Anais do Workshop de Informática na Escola. 2011. p. 1440-1443.

Roland, L. C. et al. (2010) "Jogos educacionais". Renote, v. 2, n. 1.

Rose, J. C. (2012) "Análise comportamental da aprendizagem de leitura e escrita." Rebac-Revista Brasileira de Análise do Comportamento, v. 1, n. 1, p. 29-50.

Neto, S. R. S. (2013) "Jogos Educacionais como Ferramenta de Auxílio em Sala de Aula”. In: II Congresso Brasileiro de Informática na Educação (CBIE 2013) XIX Workshop de Informática na Escola (WIE 2013).

Todos pela educação (2016) Disponível em: $<$ http://www.todospelaeducacao.org.br/sala-de-imprensa/releases/34223/relatorio-domovimento-todos-pela-educacao-apresenta-estudos-ineditos/ $>$. Acesso em: Jun. 2016.

Vasconcelos, C. C. Ensino-aprendizagem da matemática: velhos problemas, novos desafios. Revista Millenium, n. 20, 2000.

Vygotsky, L. S. (1998) "A formação social da mente - o Desenvolvimento dos Processos Psicológicos Superiores”. 4. ed. São Paulo: Martins Fontes. 